\title{
Percepção de professoras de ensino médio e fundamental sobre a homofobia na escola em Santa Maria (Rio Grande do Sul / Brasil)
}

\section{Elementary and High School teachers'perception on homophobia at school in Santa Maria (Rio Grande do Sul / Brazil)}

\author{
Zulmira Newlands Borges ${ }^{1}$ \\ Guilherme Rodrigues Passamani ${ }^{2}$ \\ Mariane Inês Ohlweiler ${ }^{3}$ \\ Muriel Bulsing ${ }^{4}$
}

1 Doutora em Antropologia Social (1998). Professora do Departamento de Ciências Sociais e do Mestrado em Ciências Sociais da Universidade Federal de Santa Maria (UFSM). Pós-doutorado pela Faculdade de Educação da Universidade Federal do Rio Grande do Sul (FACED/UFRGS, 2007). Líder do Grupo de Estudos e Pesquisas em Cultura, Gênero e Saúde da Universidade Federal de Santa Maria (GEPACS/UFSM), Brasil

2 Professor do Curso de Ciências Sociais da Universidade Federal de Mato Grosso do Sul (UFMS-CPNV). Mestre em História-Latino-Americana pela Universidade Federal de Santa Maria (UFSM). Bacharel e licenciado em Ciências Sociais e História pela Universidade Federal de Santa Maria (UFSM). Líder do Grupo de Pesquisa em Inclusão e Diversidade da Universidade Federal de Mato Grosso do Sul (GPIDI/UFMS), Brasil

3 Doutoranda em Educação no Programa de Pós-Graduação em Educação pela Universidade Federal do Rio Grande do Sul (UFRGS). Mestre em Educação e licenciada em Pedagogia pela Universidade Federal do Rio Grande do Sul (UFRGS), Brasil

4 Bacharel em Ciências Sociais pela Universidade Federal de Santa Maria (UFSM) e graduanda de Licenciatura em Sociologia na modalidade a distância pela Universidade Aberta do Brasil/Universidade Federal de Santa Maria (UAB/UFSM). Assistente desta pesquisa com bolsa de iniciação científica pelo Programa Institucional de Bolsas de Iniciação Científica (PIBIC), Brasil. 


\title{
RESUMO
}

Em pesquisa com escolas estaduais na cidade de Santa Maria (RS), em que entrevistamos 20 professoras, observou-se que não existe a preocupação formal com questões de sexualidade na escola. Discriminações e brincadeiras em torno dos que são ou parecem ser homossexuais são geralmente ignoradas. Professoras entrevistadas relatam grandes dificuldades em tratar o tema homofobia em sala de aula. Os dados indicam que é necessário um trabalho educativo com diretoras de escolas e com orientadoras pedagógicas para que estas sejam sensibilizadas para a questão e possam dar suporte para as professoras que tomam para si a tarefa de abordar temas como a homofobia.

Palavras-chave: homofobia; sexualidade; educação; escola.

\begin{abstract}
In research on state schools in the city of Santa Maria (RS), in which 20 teachers were interviewed, it was observed that there is no formal concern with sexuality issues at school. Discrimination and jokes around those who are or appear to be homosexuals are generally ignored. Teachers interviewed reported great difficulty in dealing with the issue homophobia in the classroom. The data indicated that educational work with school principals and mentors is necessary so that they can be sensitized to the issue and can provide support for teachers who take upon themselves the task of addressing issues such as homophobia.

Keywords: homophobia; sexuality; education; school.
\end{abstract}

\section{Introdução}

Este artigo, que destaca a problemática da homofobia na escola, possui como recorte um estudo de caso com as escolas estaduais de Santa Maria (RS). Considera-se importante pensar a discriminação homofóbica na escola, espaço público de frequência obrigatória onde crianças, jovens e adolescentes começam a construir suas identidades sociais e a estabelecer relações com o mundo dos afetos. Regras, limites, permissões e proibições, depois da família, em grande medida, são transmitidos para os jovens através da escola.

Numa época em que discussões e publicações acerca de gênero e sexualidade na educação já se encontram em grande número em livros, revistas e 
periódicos variados, torna-se pertinente o aprofundamento e uma abordagem mais específica sobre a diversidade sexual na escola. Afinal, é nela que se observam casos cada vez mais frequentes na mídia, situações de preconceito que geram comportamentos discriminatórios diante das mais diversas diferenças. Esse tipo de comportamento por parte de algumas crianças e adolescentes diante de seus colegas ficou conhecido como bullying, termo em inglês que designa comportamentos violentos na escola no intuito de intimidar e agredir alunos e alunas que não fazem parte de determinado padrão social.

Essa não é uma realidade nova. A novidade está na visibilidade atualmente dada ao tema. Muitos indivíduos considerados fora do padrão ideal estão sujeitos a tratamentos discriminatórios na escola. O que causa maior estranhamento é a falta de preparo da sociedade para minimizar os efeitos dessas situações que se impõem no cotidiano escolar. Neste ensaio, trataremos de um tipo específico de bullying, isto é, aquele que discrimina todos os indivíduos que supostamente não se enquadram nos padrões da heteronormatividade da nossa sociedade.

Como se sabe, os indivíduos são resultado de suas relações estabelecidas em sociedade. Somos e nos construímos em contato com os outros. Nesse sentido, a discriminação homofóbica chega até a escola de várias formas, podendo ser simétrica - entre alunos, jovens da mesma idade ou do mesmo ano escolar - ou assimétrica, vinda de brincadeiras, risos, silêncios ou mesmo da indiferença dos professores ou funcionários da instituição que deveriam educá-los e protegê-los. Entretanto, seja qual for a forma em que a violência homofóbica se insere na escola, ela reflete a sociedade mais ampla e seus grupos familiares, edificada sobre a matriz do preconceito à diferença. Quando os agressores compartilham o mesmo ambiente escolar, o bullying homofóbico é realizado igualmente por crianças, jovens e adolescentes que, por meio de uma violência simbólica e/ou física, insinuam, criticam e excluem. Esse comportamento estabelece, para as vítimas, um sentimento de não pertencimento ao grupo hegemônico heterossexual e faz nascer uma sensação de desconforto e intimidação diante dos demais e, em muitos casos, leva à evasão escolar. Tais crianças adquirem traumas de ordens variadas: psíquicas, sociais e morais ${ }^{5}$.

Assim, o presente ensaio problematiza a questão da homofobia nas escolas de Santa Maria, à luz de uma teoria que já enfoca a questão, bem como busca algumas raízes do pensamento e da prática homofóbicos. Tais questões são fundamentais para uma discussão mais profunda sobre o tema.

Em um primeiro momento, discutiremos a problemática da homofobia

5 Por trauma compreendemos aquilo que marca a consciência, inscreve-se na memória e no corpo e cria diferentes formas de relação com os outros e com o mundo, constituindo assim a própria subjetividade (BORRILLO, 2001). 
para em seguida analisá-la no contexto dos gêneros, das masculinidades e das sexualidades. No terceiro momento passaremos a apresentar os dados coletados através de pesquisas realizadas com as professoras nas escolas, através de entrevistas semiestruturadas ${ }^{6}$.

\section{Para um debate sobre homofobia}

Entre as diversas formas atuais de preconceito e discriminação, a homofobia ainda é a menos discutida e a mais consentida na presença de outras pessoas que não sofrem o ato homofóbico em si. Sem desconhecer a complexidade desse conceito para diferentes campos do conhecimento e teorias acadêmicas, optamos aqui por uma definição em específico, qual seja, a de Borrillo (2001) toda atitude hostil que tem como foco os homossexuais, homens ou mulheres. Em termos específicos, a homofobia consiste em designar o outro como inferior, contrário ou anormal, de modo que sua diferença o coloca fora do universo comum dos humanos, em situação de abjeto. Nas palavras do autor, homofobia é:

la hostilidad general, psicológica y social, respecto a aquellos y aquellas de quienes se supone que desean a individuos de su propio sexo o tienen prácticas sexuales con ellos. Forma específica del sexismo, la homofobia rechaza también a todos los que no se conforman con el papel predeterminado por su sexo biológico. Construcción ideológica consistente en la promoción de una forma de sexualidad (hetero) en detrimento de otra (homo), la homofobia organiza una jerarquización de las sexualidades y extrae de ella consecuencias políticas. (BORRILLO, 2001, p. 36).

Em consonância com a definição de Borrillo (2001), Teixeira Filho e outros (2007, p. 303) conceituam homofobia como "qualquer sentimento de ódio, repulsa, aversão, descrédito ou desprezo à pessoa homossexual (ou àquelas que se presume serem) ou a tudo que faça referência à homossexualidade no outro ou em si próprio".

Há uma situação que merece atenção, do ponto de vista etimológico, e

6 É importante destacar que todas as nossas entrevistadas eram mulheres com exceção de um diretor de escola. Sendo assim, optamos nesse artigo, a usar sempre o feminino para apresentar as entrevistas. 
que gera alguns problemas. Alguns pesquisadores fazem uma crítica ao termo homofobia porque ele poderia representar uma problemática de nível pessoal do ponto de vista psíquico, sendo uma entre tantas neuroses. Qual o grande problema advindo dessa situação? Se a homofobia é uma simples neurose, ela pode ser tratada seja pela Psicologia, seja pela Psiquiatria. É algo na contramão do que se entende convencionalmente por homofobia, isto é, uma aversão social e coletiva a tudo aquilo que aparente ser homossexual. O problema é que o foco continua sendo a homossexualidade, e a sugestão dos que criticam o termo homofobia é justamente questionar a normatização sobre a sexualidade, exercida especialmente pela nossa cultura judaico-cristã, que impôs a heterossexualidade como o modelo ideal e saudável de sexualidade.

De acordo com Davi (2005, p. 119), a homofobia assenta-se e ainda permanece embasada em três justificativas: "a dominação masculina e o ideal de virilidade, o dogma da sexualidade voltada para a reprodução, que norteia os ditames morais das diversas religiões humanas ocidentais, e a heterossexualidade com 'norma' sexual 'natural"'. A partir desses três elementos, torna-se pertinente - para aprofundar o conceito de homofobia -, esclarecer o que compreendemos por heterocentrismo, palavra que, segundo as palavras de Teixeira Filho e outros (2007, p. 304),

refere-se a um modo de pensar, agir e sentir pautado na arbitrariedade do sexo biológico usado como premissa "verdadeira sobre os sexos", que posiciona a heterossexualidade como referência primeira dos desejos, ideais, princípios e valores, $\mathrm{o}$ qual produz, por sua vez, um sentimento de superioridade em relação a todas as outras manifestações da orientação e/ou identidade sexual.

Deve-se levar em consideração, ainda, que a identidade sexual e outras identidades sociais, assim como as diversas formas de vida, se produzem em relação às ofertas culturais e às condições institucionais da escola (EPSTEIN; JOHNSON, 2000). Prova disso são os dados desta e de outras pesquisas ${ }^{7}$, em que muitas das situações homofóbicas relatadas pelos sujeitos entrevistados têm sua origem ou aconteceram de fato na escola, a ponto de deixar alguns alunos impossibilitados psicologicamente de frequentá-la, por causa da discriminação que sofreram.

7 Há uma vasta bibliografia sobre os efeitos provocados por atos homofóbicos nas escolas. Ver, em especial, o levantamento de pesquisas a respeito realizado por Junqueira (2009) e Borges e Meyer (2008). 
A situação de desvalorização e abjeção a que são submetidos os que não compartilham da norma heterossexual é bem mais disseminada do que se imagina. O grau de homofobia no país é alarmante ${ }^{8}$. O Brasil mata, por ano, aproximadamente 120 homossexuais, um indício evidente de desrespeito à livre expressão sexual dos que não se enquadram nos padrões heteronormativos (JUNQUEIRA, 2007). Nós institucionalizamos no Brasil a discriminação aos homossexuais, na medida em que um percentual de menos de $10 \%$ dos assassinos de homossexuais são presos, condenados ou mesmo indiciados pelos crimes cometidos. Esses dados do Programa Nacional de DST e AIDS (BRASIL, 2006) colocam em alerta não apenas a população $\mathrm{LGBT}^{9}$, porque se apresenta como bastante vulnerável, mas toda a sociedade que vê a impunidade estabelecer-se como norma.

Não se trata, no entanto, de uma questão meramente homofóbica. Há outros fatores envolvidos. Os recortes de classe são muito significativos nesse caso, pois o acesso à Justiça dos menos favorecidos torna-se uma verdadeira via crucis. Assim, os homossexuais que são vítimas de violência e que possuem maior poder aquisitivo têm mais condições de reivindicar seus direitos (RAMOS; CARRARA, 2006). Ainda assim, muitas vezes, preferem a impunidade dos agressores ao desvelamento de sua homossexualidade.

O termo homofobia, no sentido consagrado pela Unesco, é uma forma preconceituosa de tratamento dispensada aos homossexuais, capaz de gerar discriminações a todo e qualquer indivíduo que seja nomeado como tal, fazendo com que sua dignidade seja ferida e desrespeitada (CASTRO; ABRAMOVAY; SILVA, 2004). Portanto, fica claro a partir do exposto, que a homofobia se apresenta de forma variada. Atos homofóbicos podem traduzir-se em situações limites, como agressões físicas e homicídios, mas desvelam-se em formas mais sutis, como as de violência velada (simbólica), ou seja, através de piadas, brincadeiras jocosas ou mesmo comentários e insinuações de desejo de afastamento de pessoas reconhecidas como homossexuais.

A escola, nesse sentido, através de sua legislação específica, precisa implementar políticas que corrijam uma defasagem de informação e conhecimento

8 Destacamos, aqui, o trabalho pioneiro e criterioso sobre crimes envolvendo homofobia do GGB (Grupo Gay da Bahia), o qual se difunde hoje entre as principais ONGs e movimentos sociais LGBT através dos Centros de Referência, na documentação da violência contra homossexuais no Brasil. Segundo o site: "No Brasil registra-se, portanto, um crime de ódio anti-homossexual a cada três dias. Dois por semana. Oito por mês. Uma média de 100 homicídios anuais. A partir de 2000 essa média vem aumentando: 125 crimes por ano, sendo que em 2004 atingiu o recorde: 158 homicídios." (GRUPO GAY DA BAHIA, 2005).

9 LGBT significa Lésbicas, Gays, Bissexuais e Transgêneros. São inúmeras as combinações possíveis e indicam diferentes momentos e coalizões dos movimentos sociais, formando uma "verdadeira sopa de letrinhas" (FACHINNI, 2005). 
que falta aos alunos em casa e nas suas redes de sociabilidades mais próximas. Em vista disso é que a professora Sandra ${ }^{10}$ entende que a homofobia

[...] acontece, desde os pequenininhos, bem como eu te falei. "Aho fulano é isso é aquilo", eles chamam aquele aluno que é mais... tem os meninos mais afeminados, tem né, isso ai tem, que foge do padrão daquele machismo e eles falam né [...]. "Fulaninho chamou de bicha" e dai eu pergunto "Mas o que que é isso? Por que que ele não pode ser isso? Por que que tu vai rotular essa pessoa? Cada um sabe de si." Eu sempre devolvo, pergunto pra eles o que que é, o que que significa, como é que é ser isso, se não a criança só vai reproduzindo, entendeu? Só vai falando, falando... Porque preconceito é muitas vezes a falta do conceito né? A falta de tu ter a... saber sobre a coisa em si, sobre o assunto. (Sandra).

No entanto não basta que a discussão esteja na escola. É preciso saber qual a qualidade do debate que está sendo feito. Outro ponto recorrente na pesquisa diz respeito ao fato de ainda vermos nas escolas as questões referentes à sexualidade sendo apresentadas, quase que exclusivamente, pelas disciplinas biomédicas. $\mathrm{Ou}$ seja, a abordagem que predomina ainda é baseada em uma visão biologizante da sexualidade. A discussão sobre a diversidade de orientações sexuais é ainda marginal ou ausente dentro das escolas (BORGES; MEYER, 2008).

Tentando reverter essa situação, os movimentos sociais e o governo brasileiro criaram o programa Brasil Sem Homofobia, na intenção de incentivar cursos de formação sobre a diversidade sexual direcionados para professores/ as, buscando fortalecer a perspectiva de direitos sexuais como direitos humanos, situando a sexualidade entre os direitos fundamentais para o livre e pleno exercício da cidadania ${ }^{11}$. Este tipo de iniciativa governamental vai ao encontro do que preconizam Dinis e Cavalcanti (2008, p. 107) sobre a necessidade de ultrapassar "a ideia de tolerância por meio de políticas que questionem as próprias normas que produzem e categorizam as identidades sexuais e de gênero".

10 Adiantamos que os nomes são fictícios para preservar a identidade das professoras entrevistadas. Sandra, 51 anos, é formada em Educação Infantil e atua como professora há 30 anos. Atualmente, além da educação infantil, ela dá aulas para o $1^{\circ}$ ano do ensino médio.

11 O programa recebeu apoio do Ministério da Educação e foram lançados muitos editais para financiar projetos de formação de professores/as de escolas. 


\section{A construção social da homofobia}

A homofobia tem muitas facetas. Uma delas, talvez das mais comuns, é o machismo. Trata-se de uma prática disseminada em muitas sociedades humanas, estruturante das relações sociais, englobando tanto homens quanto mulheres. O machismo não é apenas alguma coisa que pessoas distantes relataram em depoimentos históricos. Antes, é uma situação que vivemos e revivemos, quase todos, cotidianamente. Ele é resultado de ações, gestos, silêncios, proibições, agressões ou indiferença de um homem sobre mulheres, crianças ou qualquer outra pessoa que se encontre em uma posição socialmente entendida como inferior. Parece pertinente a definição de machismo presente na abordagem de uma psicóloga mexicana, Marina Castañeda (2006, p. 16):

O machismo pode ser definido como um conjunto de crenças, atitudes e condutas que repousam sobre duas ideias básicas: por um lado, a polarização dos sexos, isto é, uma contraposição do masculino e do feminino segundo a qual são não apenas diferentes, mas mutuamente excludentes; por outro, a superioridade do masculino nas áreas que os homens consideram importantes. Assim, o machismo engloba uma série de definições sobre o que significa ser homem e ser mulher, bem como toda uma forma de vida baseada nele.

Para a autora, há todo um sistema que se encarrega de dar corpo e sustentação ao machismo. Esse sistema torna a diferença entre os sexos uma questão maior, tão maior que chega a ser excludente. Além disso, no machismo há a construção da hierarquização entre os sexos a partir de uma lógica cultural que privilegia o masculino em detrimento do feminino e de tudo aquilo que dele se aproximar. Cria-se uma ideia de homem que precisa constantemente ser reificada desde essa lógica de exclusão e sobreposição diante de tudo aquilo que foge ao pré-estabelecido. ${ }^{12} \mathrm{O}$ legado da cultura machista é muito claro: não basta ser homem, é preciso ser mais homem que a maioria dos homens. Por isso, os

12 Vale destacar que o relatório da UNESCO sobre juventude e sexualidade afirma que os homens são mais homofóbicos que as mulheres e que há maior discriminação quando o comportamento de gênero não corresponde ao sexo biológico como em casos de homens femininos e mulheres masculinizadas (ABRAMOVAY, 2004). Os nossos dados corroboram esses achados e por isso há predomínio de relatos sobre homossexualidade masculina sempre vista como mais desestabilizadora da ordem social. 
homossexuais são os alvos preferidos dos machistas, que podem fazer críticas e ofensas sobre a homossexualidade que gostariam de dirigir às mulheres, pois o machismo constrói-se a partir da extrema valorização da força e da virilidade e através do desprezo às atitudes femininas, especialmente quando elas estão fora de seu lugar convencional, que é o corpo da mulher, em um nítido comportamento misógino.

Castañeda ressalta que desde muito cedo os meninos precisam aprender a sufocar qualquer diferença ou inaptidão. Precisam assemelhar-se, ainda que isso represente uma afronta aos seus desejos mais íntimos. A autora percebe que a norma é de tal forma efetiva que mergulha na subjetividade do indivíduo quando da formação de sua personalidade, a fim de que já desde esse momento se torne impregnado pelos valores machistas que constroem os ideais de masculinidade hegemônica.

Esse processo não se faz sem traumas. Crianças sensíveis, tímidas, estudiosas são facilmente rotuladas de homossexuais, sem mesmo entender o que isso significa. E mais, muitas vezes, sem qualquer inclinação para o homoerotismo. São isoladas nas turmas porque tinham mais afinidades com as meninas do que com os meninos; porque preferiam de ver as meninas dançar ballet na sala de recreação a estar correndo atrás da bola de futebol. Preferiam o mundo encantado das histórias infantis, dos contos de fada, a estar com os outros moleques, jogando bola de gude. Nunca gostaram dos filmes de ação ou terror e os deveres escolares eram horas prazerosas. Essas situações não fazem de uma criança de 10 ou 12 anos um homossexual.

\section{A homofobia nas escolas de Santa Maria}

Pensar sobre a homofobia na escola torna-se uma atitude ética e política, de consideração ao outro como sujeito de direitos em uma instituição em que palavras como inclusão (e no que preconizamos aqui como inclusão da diversidade sexual) nem precisariam ser mencionadas e tão reivindicadas, especialmente nesse momento em que a educação, por si só, se quer como direito democrático. Além disso, a escola é o espaço social que concentra por excelência uma variada e complexa trama de relações interpessoais. É nela que colidem, refletem e eclodem muitos dos problemas mais comuns e, por que não dizer também, singulares da sociedade. 
A pesquisa, cujo recorte de dados trazemos aqui, foi realizada em Santa Maria, iniciada em 2008 e concluída em $2009^{13}$. Nosso objetivo foi identificar valores culturais que possibilitam tanto silenciar quanto reagir a discriminações dentro da escola, bem como analisar as percepções destas professoras acerca do compromisso e da responsabilidade da escola no enfrentamento de questões como discriminações de gênero e homofobia no âmbito escolar. Com esse intuito, realizamos entrevistas com 20 professoras ${ }^{14}$ de dez escolas estaduais de Santa Maria. A seleção dessas escolas foi realizada a partir de um projeto de extensão anterior, vinculado ao Grupo de Pesquisa em Cultura, Corpo e Saúde, intitulado "Discutindo gênero e sexualidade nas escolas sob uma perspectiva antropológica". Nesse projeto tínhamos selecionado 15 escolas estaduais do município de Santa Maria por serem de grande porte e de localização central; dessas escolas, após contatos com a $8^{\text {a }}$ Coordenadoria Regional de Educação e com a Secretaria Municipal de Educação, recebemos Carta de Apresentação para abordarmos 9 (nove) escolas estaduais.

Cada entrevista foi previamente marcada e realizada no local conveniente, de acordo com a escolha de cada professora, tendo no máximo duas horas de duração ${ }^{15}$. A entrevista semidiretiva, como técnica de coleta de dados, proporcionou um aprofundamento na temática e permitiu às informantes uma liberdade maior para expor ideias, sentimentos e experiências, assim como nos possibilitou explorar a percepção das professoras quanto à cultura escolar, em relação a padrões de comportamento e discursos predominantes na escola. Essa metodologia ainda nos forneceu o registro em detalhes de casos nos quais surgiram questões de gênero e sexualidade e a maneira como foram tratados pelas professoras e pela escola. Alguns resultados devem ser destacados com ênfase à vulnerabilidade programática discutida em Borges e Meyer (2008). A homofobia na escola parece estar alicerçada por uma vulnerabilidade programática na medida em que a ausência de apoio institucional para discussão

13 A proposta de investigar sobre a percepção de professoras do ensino médio e fundamental sobre a homofobia na escola em Santa Maria parte de uma pesquisa também voltada ao espaço escolar (BORGES; MEYER, 2008). Os dados relatados naquele estudo geraram muitas questões e curiosidades que nos motivaram a estudar sobre qual seria a situação em uma cidade do interior do Rio Grande do Sul.

14 A seleção das professoras foi mediada pela direção de cada escola que nos indicou professoras que poderiam estar mais aptas a participarem da pesquisa e estas, após apresentarmos a pesquisa, optaram por participar, ou não, de acordo com a sua disponibilidade.

15 Todas as entrevistas foram gravadas, transcritas e analisadas a partir da autorização por escrito das participantes, através do Termo de Consentimento Livre e Esclarecido e da entrega do Termo de Confidencialidade. O projeto foi registrado e aprovado pelo comitê de ética da UFSM em 2009. 
do tema viabiliza que brincadeiras homofóbicas sejam aceitas e a prioridade dada ao conteúdo pré-estabelecido permite o silêncio frente a discriminações e injúrias. Assim como a falta de inclusão das famílias e ou cuidadoras/es e a falta de educação continuada para as professoras sobre essas questões culmina com a ausência de reflexão e questionamentos sobre a heteronormatividade. A articulação entre esses elementos e o seu respectivo conjunto colabora para vulnerabilizar todos aqueles que são vistos como diferentes e que são apontados como fora da norma heterossexual.

Em consonância com os dados da pesquisa de Borges e Meyer (2008), não havia preocupação formal e institucional com questões de sexualidade na escola. Os temas relativos à sexualidade, gênero e discriminações ficam a cargo do interesse e da boa vontade das professoras que, voluntariamente, se dispõem a tratar o assunto em sala de aula ${ }^{16}$. Algumas entrevistadas relataram dificuldades em tratar o tema homofobia no ambiente escolar. Os dados indicam que é necessário que seja feito um trabalho educativo com as diretoras de escolas e com orientadoras pedagógicas, para que sejam sensibilizados para a questão e possam dar suporte às professoras que tomam para si a tarefa de abordar temas como a homofobia. As dificuldades são de toda ordem, como pontua a professora Ana Maria ${ }^{17}$ :

Eu lembro que uns dois, três anos atrás, eu tinha a $8^{a}$ série e nós falamos justamente sobre opção sexual. O título era "opções sexuais" e aí falamos sobre homossexualismo né, e... eu sei que no final da aula eu disse que tinha um pesquisador americano que tinha dito que "quem não acreditava no terceiro sexo que troque de planeta" e a minha surpresa foi que no final da aula eles estavam fazendo uma excursão pra Marte. (Ana Maria).

Para ilustrar o grau de despreparo das escolas e de suas respectivas diretorias, vale a pena descrevermos uma situação de campo. Em um dos colégios, quando fomos solicitar a autorização para a realização da pesquisa o diretor da escola nos recebeu muito atenciosamente. No momento em que dissemos o

16 Vale a pena destacar que, assim como no trabalho de Borges e Meyer (2008), só aceitaram participar da pesquisa professoras do sexo feminino; isso talvez esteja relacionado ao tema, já que muitas pesquisas demonstraram que as mulheres sentem menor rejeição à homossexualidade do que os homens, conforme constatado em: Higgins, Zheng, Liu e Sun (2002); Whitley e Kite (1995 apud MARINHO et al., 2004); e Gravad (apud JUNQUEIRA, 2009).

17 Ana Maria possui formação em Letras, atua como professora há 15 anos e atualmente leciona para a $5^{\circ}$ e $6^{\circ}$ série do ensino fundamental. 
objetivo da pesquisa, ele reagiu com ansiedade, nos interrompendo e dizendo que era muito importante a nossa pesquisa, pois na escola em que estávamos havia muitos alunos que afrontavam os colegas com o seu comportamento. Meninos iam vestidos de meninas, com maquiagem e tudo e isso, segundo ele, era um desrespeito com os colegas e com as professoras. A escola, segundo o diretor, não tinha nada a ver com a preferência sexual dos alunos e com o que eles faziam, ou não, fora da escola. Mas ali dentro ele achava um desrespeito duas meninas se beijarem na boca em pleno horário do recreio e um rapazinho ir todo vestido de mulher, pois de acordo com ele, era somente para chamar atenção. A sua posição era evidente quanto à necessidade de obter um bom comportamento dentro da escola, o que incluía, em nossa interpretação, uma educação para uma boa adequação de gênero e de respeito à norma heterossexual.

Embora a preocupação em relação à abordagem e à discussão sobre sexualidade, gênero e discriminação exista em muitas escolas, persiste a necessidade de uma análise e de questionamentos específicos. Assim, a partir de uma teoria calcada na realidade, poderiam insurgir parâmetros e objetivos, de modo que tais temas fossem tratados adequadamente, respeitando a alteridade de educandos e educadores.

As escolas pesquisadas não têm um plano específico ou ao menos algo como uma determinação refletida e guiada para lidar com as situações que envolvem gênero e sexualidade, tanto em termos de informações interdisciplinares acerca da temática quanto em termos de ações em casos de discriminações. Assim, as professoras acabam lidando com as situações de acordo com os seus próprios valores, os seus conhecimentos específicos e contextuais e a partir de suas próprias possibilidades que são limitadas tanto pelo formalismo escolar, no sentido de compartimentalizar saberes, quanto pela falta de um norte, ou seja, uma ação que seja informada e que dê respaldo ao professor na sua tarefa de educar de forma humanista e inclusiva. A professora Maria Clara ${ }^{18}$ apresenta uma situação, ocorrida em sua sala de aula, que demonstra a presença do preconceito homofóbico na escola e a dificuldade em produzir um contradiscurso:

[...] a sala de vídeo hoje quase veio abaixo porque tem uma cena do filme que aparecem dois meninos se beijando, foi uma gritaria. Eles acham muito comum, por exemplo, se acontecer um beijo entre duas meninas, eles acham bonito, agora entre dois meninos eles não aceitam. Talvez eles não sejam assim tão explícitos, mas a gente percebe assim uma certa perseguição, com aqueles que são homossexuais ou meio diferentes. (Maria Clara).

18 Maria Clara tem 52 anos, 25 anos de profissão e atualmente dá aulas de Filosofia Política para o ensino médio. 
Nas falas das professoras, aparece com frequência a sobrecarga de funções e expectativas que a sociedade e os pais impingem sobre a escola e sobre o próprio trabalho do educador. O trabalho deste tem de dar conta não só do conteúdo de suas disciplinas, mas também do cuidado constante em relação a comportamentos e ações das crianças e adolescentes que estão sob a guarda da escola. Essa sobrecarga acaba por fazer com que muitos professores sejam obrigados a escolher os assuntos mais relevantes para serem tratados em sala de aula. Nessas condições, as questões de conteúdo ganham prevalência sobre temas transversais, que estão mais relacionados ao comportamento.

O excesso de responsabilidades expõe uma possível razão para que brincadeirinhas e alguns enfrentamentos em sala de aula acabem por ser tolerados e/ ou ignorados, pois o tempo que se leva discutindo uma brincadeirinha pode ser o tempo necessário para vencer o conteúdo. A maioria das professoras reconhece que a existência de brincadeirinhas em torno da questão da homossexualidade é como um reflexo da homofobia existente na sociedade. O que difere, porém, é o valor dado pelas professoras a estas brincadeirinhas. Mônica ${ }^{19}$, por exemplo, nos diz não se lembrar de nenhum fato que tenha sido realmente grave:

[...] o que mais acontece são essas discriminações dentro da sala de aula, quando tem alunos homossexuais, mas eu não lembro de nenhuma coisa grave que tenha acontecido assim... Fica muito na questão da brincadeira. (Mônica).

Sendo assim, muitas discriminações e brincadeiras em torno dos que são ou parecem ser homossexuais são geralmente ignoradas, porque há uma dificuldade no ambiente escolar para definir o que é uma situação homofóbica. O que é homofobia pra uns é apenas brincadeira para outros. Aí reside um dos problemas do conceito; se não houver agressão física extrema que ameace a vida de alguém, o resto parece ser tolerado como uma brincadeira normal dos adolescentes. A questão parece ser sobre esse limite do que é ou não aceitável. As professoras realmente se consideram contra a homofobia, mas é muito comum também entenderem que determinados comportamentos e vestimentas são uma afronta à vida na escola. Como já foi referido antes, é comum a noção de que o bom comportamento dentro da escola deva incluir uma adequação do gênero ao sexo e também à heteronormatividade.

19 Mônica tem 39 anos, formada em letras com especialização em literatura infantil brasileira, atualmente dá aulas para o ensino médio. 
Ainda assim, várias professoras entrevistadas reconhecem as brincadeiras em sala de aula como reflexos de discriminações homofóbicas. Entretanto, não veem gravidade nelas. Será mesmo que as brincadeiras constantes e constrangedoras não são graves? As que percebem a própria sala de aula como um lócus privilegiado para reflexão acerca dessas questões se esforçam para iniciar um combate a discriminações. No entanto, por falta de tempo ou por condição de acúmulo de funções, sentem-se prejudicadas nesse exercício.

Outro ponto presente nas falas das professoras de Santa Maria é a falta de um envolvimento dinâmico tanto das famílias dos estudantes quanto da própria direção da escola nas situações que ocorrem em sala de aula. As professoras que consideram o tema relevante e são corajosas o suficiente para abordar questões de violência, homofobia ou abuso sexual o fazem, muitas vezes, por iniciativa própria, sem orientação formal. Algumas vezes, a boa intenção acaba criando graves problemas com as famílias e, inclusive, com a direção da escola.

Em uma das escolas, uma entrevistada nos relatou um caso no qual uma professora solicitou um trabalho aos alunos sobre abuso sexual e pedofilia. A reação das famílias dos alunos foi tão drástica que a professora foi repreendida pela direção e afastada de suas funções. As famílias consideraram que esse era um assunto a ser tratado apenas no domínio privado e não na escola. É nesse sentido que argumentamos o quanto é necessário um programa continuado de discussão sobre temas como homofobia, sexualidade, discriminação, abuso sexual, violência de gênero etc., que inclua não apenas as professoras, mas também a secretaria de educação, as direções das escolas e, especialmente, as famílias.

Com relação aos Parâmetros Curriculares Nacionais (PCNs) - que indicam que questões de gênero e sexualidade devem ser tratadas de forma transversal -, estes são, de maneira geral, conhecidos superficialmente pela escola. Nossas informantes são unânimes quando falam da necessidade de uma formação específica e continuada a esse respeito, a fim de instrumentalizar essa diretriz. Destacamos ainda que, para além do conhecimento das diretrizes apresentadas nos PCNs no item intitulado orientação sexual, é necessário perceber como, também neste documento oficial, a diversidade sexual é abordada de forma sutil.

Com base no que foi dito até aqui, podemos afirmar a existência de uma lacuna na formação pedagógica em termos de teoria e prática acerca da temática da homofobia. Enfatizamos, sobretudo, a carência relacionada ao conhecimento das questões de construção da homofobia na raiz da cultura ocidental, marcada pela distinção entre os gêneros, hierarquizando-os e desdobrando-se em um machismo hegemônico. A incidência de uma cultura hegemônica, que marca e discrimina a diferença, é percebida por algumas professoras, como é o caso de Célia ${ }^{20}$ :

20 Célia, 42 anos, formação em pedagogia, possui 21 anos de experiência e atualmente dá aulas para o ensino fundamental. 
Eu acho que, pelo que eu vejo, que tem uma questão cultural muito forte... eu já tive alunos homossexuais assumidos e existe um machismo, principalmente dos meninos, de pegar no pé dessas pessoas e às vezes o menino nem é e faz alguma coisa que lembre, que se assemelhe, então tu vê como tem alunos machistas, isso é cultural... (Célia).

A homofobia é um traço marcante em diversos setores da nossa sociedade. Isso se reflete na quase ausência de políticas públicas nesse sentido. Com relação às práticas homofóbicas na escola, vimos nas falas das professoras que o Estado pouco faz no sentido de auxiliar a educação no enfrentamento real a essas lacunas. Para as educadoras, pensar uma nova educação passa por um enfrentamento a tais temáticas, como prioridade em todos os programas de expansão escolar e melhoria de qualidade na educação, já que isso implica o cumprimento da garantia dos direitos humanos fundamentais.

Construir uma educação inclusiva, a nosso ver, é fazer com que a escola desconstrua rótulos, estereótipos e preconceitos que aparecem naturalizados em nossa cultura através de um plano curricular que apresente a diversidade sexual e de gênero em uma perspectiva contextual, contingente e relacional, através do treinamento adequado das educadoras. Esse treinamento é pré-requisito fundamental na qualificação das profissionais da educação.

\section{Considerações finais}

Não podemos negar que há avanços no combate à homofobia, o que se pode perceber em diversos fatos. Por exemplo, quando professoras se dispõem a participar de um curso sobre diversidade sexual, como relatam Borges e Meyer (2008). Ou quando as educadoras reconhecem e apontam a ausência da temática de gênero e sexualidade nos seus cursos de formação. Ainda: no momento em que uma educadora se posiciona contrariamente a injúrias dos alunos que nomeiam o colega de bicha e os questiona a respeito, incide aí uma forma de questionar a ordem heteronormativa e machista vigente que inferioriza o que não condiz com o masculino. Vale frisar, porém, que no momento em que um aluno responde à professora que não tem conhecimento das palavras que está usando para insultar o colega, não basta questionar se o/a colega é ou não é homossexual e se deveria ser assim nomeado, mas trata-se de discutir a homofobia, pois esta sim é merecedora de questionamentos, e não a homossexualidade. Como enfatiza Junqueira (2009), é necessário problematizar, desestabilizar e subverter a ho- 
mofobia. Ao nos restringirmos à classificação entre homos e heteros, limitamos a constituição do sujeito à sua orientação sexual.

A homofobia, como forma de desumanização do outro, rompe com as fronteiras mais limítrofes dos direitos humanos. No momento em que não nos posicionamos contra, em que, como educadores, silenciamos, também somos coniventes. Reiteramos, aqui, a importância da escola como espaço de enfrentamento à homofobia pelo fato de esta, diferentemente de outras formas de hostilidade, ser costumeiramente dirigida a indivíduos isolados e não a grupos constituídos ou classificados em minorias. Devido a isso, o/a homossexual costuma sofrer o preconceito solitariamente, por vezes sem apoio do seu entorno mais próximo, a família.

Infelizmente, pelo que pudemos constatar em nossa pesquisa, assim como o que Rohden (2009) analisou em seu estudo com professoras que também realizaram um curso de formação continuada sobre diversidade sexual (entre outros assuntos), é que "a tensão entre público e privado, entre escola e família opera no sentido de provocar mais paralisia do que transformação" (ROHDEN, 2009 p. 172). Essa conclusão reforça o argumento de que a abordagem da sexualidade, das questões de gênero e em especial da homofobia deve ocorrer de forma transversal e conjunta. Não basta a ação distinta somente de um/a professor/a sem o empenho de toda equipe pedagógica - elemento que reforça a necessidade de cursos de formação continuada na área. Afinal, o sistema rotativo de turmas nas escolas faz com que a cada ano os/as alunos/as interajam com novos/as e diferentes professores/as.

Embora os/as homossexuais venham adquirindo uma paulatina visibilidade (há alguns anos era extremamente sufocada, e ainda o é, em alguns lugares), é preciso atentar ao que pode se apresentar eventualmente como uma progressiva aceitação. Pois, como lembra Louro (2008, p. 21),

nem mesmo a exuberância das paradas da diversidade sexual, das feiras mix, dos festivais de filmes "alternativos" permite ignorar a longa história de marginalização e de repressão que esses grupos enfrentaram e ainda enfrentam. Não podemos tomar de modo ingênuo essa visibilidade. Se, por um lado, alguns setores sociais passam a demonstrar uma crescente aceitação da pluralidade sexual e, até mesmo, passam a consumir alguns de seus produtos culturais, por outro lado, setores tradicionais renovam (e recrudescem) seus ataques, realizando desde campanhas de retomada dos valores tradicionais da família até manifestações de extrema agressão e violência física. 
O valor atual que deve ser ressaltado, pontuado e reafirmado tanto nas escolas quanto nos cursos de formação de professores - sejam de licenciatura, sejam os que propõem uma formação continuada - é o dos direitos humanos. A orientação sexual e a sua manifestação é um direito do cidadão. Se tal direito e visibilidade ainda sofrem as aversões de setores políticos e sociais de grande representatividade, resta-nos questionar as formas de discriminação mais próximas, nas quais possamos intervir de forma mais contundente e imediata. Mesmo que de forma precária, a escola é um dos espaços onde ainda é possível discutir sobre a homofobia e sua constituição como preconceito heterossexista.

\section{REFERÊNCIAS}

ABRAMOVAY, M. Juventudes e sexualidade. Miriam Abramovay, Mary Garcia Castro e Lorena Bernadete da Silva. Brasília: UNESCO Brasil, 2004.

BORGES, Zulmira Newlands; MEYER, Dagmar Estermann. Limites e possibilidades de uma ação educativa na redução da vulnerabilidade à violência e à homofobia. Ensaio: avaliação e políticas públicas em educação, Rio de Janeiro, v. 16, n. 58, p. 59-76, mar. 2008.

BORRILLO, Daniel. Homofobia. Barcelona: Ediciones Bellaterra, 2001.

BRASIL. Ministério da Saúde. Departamento de DST, Aids e Hepatites Virais. América Latina terá guia de ações contra homofobia (11/07/2006). Disponível em: <http://www.aids.gov.br/main.asp?View=\%7BE77B47C8-3436-41E0-AC19$\mathrm{E} 1 \mathrm{~B} 215447 \mathrm{~EB} 9 \%$ 7D\&Team $=\&$ params $=i$ temID $=\%$ 7B3BF5A713-8A25-4F378BFF-4EB65BBA3CB4\%7D\%3B \&UIPartUID=\%7BD90F22DB-05D4-4644-A8F2FAD4803C8898\%7D>. Acesso em: 11/8/2010.

CASTAÑEDA, Marina. O machismo invisivel. São Paulo: A Girafa Editora, 2006.

CASTRO, Mary Garcia; ABRAMOVAY, Miriam; SILVA, Lorena Bernadette da. Juventudes e sexualidade. Brasília: UNESCO, 2004.

DAVI, Edmar Henrique Dairell. Intolerância e homossexualidade: as marcas da homofobia na Cultura Ocidental. Caderno Espaço Feminino, Uberlândia, v. 13, n. 16, p. 119-137, jan./jun. 2005.

DINIS, Nilson Fernandes; CAVALCANTI, Roberta Ferreira. Discursos sobre homossexualidade e gênero na formação em pedagogia. Pro-posições, Campinas, v. 19, n. 2 (56), p. 99-109, maio/ago. 2008. 
EPSTEIN, Debbie; JOHNSON, Richard. Sexualidades e institución escolar. Madri: Ediciones Morata, 2000.

FACCHINI, Regina. Sopa de Letrinhas? Movimento homossexual e produção de identidades coletivas nos anos 90. Rio de Janeiro: Garamond, 2005.

GRUPO GAY DA BAHIA. Assassinatos de homossexuais no Brasil: 2005. Disponível em: <http://www.ggb.org.br/assassinatos2005.html>. Acesso em: 11/8/2010.

JUNQUEIRA, Rogério Diniz. O reconhecimento da diversidade sexual e a problematização da homofobia no contexto escolar. In: RIBEIRO, Paula Regina Costa (Org.). Corpo, gênero e sexualidade: discutindo práticas educativas. Rio Grande: Editora da FURG, 2007.

. Introdução - Homofobia nas Escolas: um problema de todos. In: JUNQUEIRA, Rogério Diniz. (Org.). Diversidade sexual na educação: problematizações sobre a homofobia nas escolas. Brasília: Ministério da Educação / Secretaria de Educação Continuada, Alfabetização e Diversidade / UNESCO, 2009.

LOURO, Guacira Lopes. Gênero e sexualidade: pedagogias contemporâneas. Proposições, Campinas, v. 19, n. 2 (56), p. 99-109, maio/ago. 2008.

MARINHO, Carla de A. et al. Adaptação da escala de homofobia implícita e explícita ao contexto brasileiro. Paidéia, Ribeirão Preto, v. 14, n. 29, p. 371-379, 2004.

RAMOS, Silvia; CARRARA, Sergio. A constituição da problemática da violência contra homossexuais: a articulação entre ativismo e academia na elaboração de políticas públicas. Physis: Revista de Saúde Coletiva, Rio de Janeiro, v. 16, n. 2, p. 185-205, 2006.

ROHDEN, Fabíola. Gênero, sexualidade e raça/etnia: desafios transversais na formação do professor. Cadernos de Pesquisa, São Paulo, v. 39, n. 136, p. 157-174, jan./abr. 2009.

TEIXEIRA FILHO, Fernando S.; TOLEDO, Lívia Gonsalves; GODINHO, Pedro Henrique. A homofobia na representação de mães heterossexuais sobre a homoparentalidade. In: GROSSI, Miriam; UZIEL, Anna Paula; MELLO, Luiz (Org.). Conjugalidades, parentalidades e identidades lésbicas, gays e travestis. Rio de Janeiro: Garamond, 2007. p. 301-319.

Texto recebido em junho de 2010 .

Texto aprovado em setembro de 2010 . 